\title{
Role of camylofin and its combinations in obstetrics and gynaecological practice: a review of Indian evidence
}

\author{
Niranjan Mayadeo* \\ Department of Obstetrics and Gynecology, Lokmanya Tilak Municipal Medical College and Hospital, Mumbai, \\ Maharashtra, India
}

Received: 16 December 2018

Accepted: 21 December 2018

*Correspondence:

Dr. Niranjan Mayadeo,

E-mail: drmayadeo@gmail.com

Copyright: () the author(s), publisher and licensee Medip Academy. This is an open-access article distributed under the terms of the Creative Commons Attribution Non-Commercial License, which permits unrestricted non-commercial use, distribution, and reproduction in any medium, provided the original work is properly cited.

\begin{abstract}
Anti-spasmodic drugs like camylofin are used in obstetrics and gynaecological practice for broadly two conditions spasmodic abdominal pain and management of prolonged labor. Camylofin has been in use in India for almost six decades. As a spasmolytic, camylofin has demonstrated good efficacy and tolerability, both in the management of abdominal spasmodic pain and in augmentation of labor. Literature evidences has suggested that camylofin has demonstrated a statistically significant superiority, such as higher spasmolytic potency compared to other antispasmodics like drotaverine, hyoscine and valethamate. In some studies, camylofin maintained the superior efficacy, despite being given as a single dose compared to repeat doses of comparator drugs. Also, in augmentation of labor, camylofin single dose demonstrated superior efficacy when the comparator arm was given a combination of two antispasmodic drugs i.e. hyoscine and valethamate in three doses at hourly intervals. Clinical studies in abdominal colic pain revealed significant superiority of the camylofin-paracetamol combination over dicylomine paracetamol combination, this despite the camylofin combination containing 300mg paracetamol as compared to the dicyclomine combination containing 500mg paracetamol. Similar results, highlighting better outcomes in abdominal colic of different types, was shown in studies comparing camylofin-diclofenac combination compared with hyoscine (in renal colic) and also camylofin-mefenamic acid combination compared with dicyclomine-mefenamic acid combination (in menstrual colic). All the above clinical study results resonate in the findings of a recent survey with gynaecologists across the country, which showed that camylofin is considered as the anti-spasmodic most suitable for female patients compared to drotaverine, dicyclomine and hyoscine. Given the availability of strong clinical trial data in Indian women patients, camylofin along with its combinations holds a strong place in the armamentarium of practicing obstetricians and gynaecologists and can be a preferred choice of therapy in treatment protocols of abdominal spasmodic pain and augmentation of labor.
\end{abstract}

Keywords: Abdominal colic, Anti-spasmodic, Camylofin, Labor

\section{INTRODUCTION}

In the Indian context, the labelled used of anti-spasmodic drugs in obstetrics and gynaecological practice is for broadly two conditions: i.e. abdominal pain (abdominal colic) and management of prolonged labor (in active phase of labor). Anti-spasmodic drugs used in this context include drotaverine, camylofin, dicyclomine, hyoscine and valethamate. While in the management of prolonged labor, these antispasmodics are used as single agents, for symptomatic relief in abdominal colic they are used both as single agents as well in combination with other analgesics like paracetamol and NSAIDs like diclofenac, mefenamic acid etc.

The pharmacological properties of camylofin as an antispasmodic, were first described by Brock in 1951., Camylofin is a potent anti-spasmodic, that finds use in 
the gynaecological practice for symptomatic relief in cases of abdominal colic. ${ }^{3}$ In obstetric practice it not only hastens cervical dilatation for augmentation of labor, but also provides enhanced analgesia when given along drugs like tramadol. ${ }^{4,5,6}$ Camylofin has been available in India since $1958 .^{7}$ Ever since, the drug has traversed almost six decades of clinical use and continues to be a preferred antispasmodic for a variety of spasmodic pains of abdominal origin. 4 The Indian experience with this drug along these years has been captured in several clinical studies, both for augmentation of labor and pain relief in abdominal colic. ${ }^{3,4,6,8}$ The current review presents the clinical role and findings of different studies investigating the efficacy and tolerability of camylofin and its combinations in the aforesaid indications in Indian patients.

\section{METHODOLOGY}

Literature search for studies on camylofin in Indian patients revealed twelve studies. Of these studies four studies reported the efficacy and tolerability of both camylofin as well as its combinations in colicky abdominal pain of various origins. Five studies reported the efficacy and tolerability of camylofin in augmentation of labor. The remaining three were non-clinical studies reporting the preferences and perception of clinicians on various antispasmodics. Of relevance amongst these three is one study reporting the perceptions and preferences of gynaecologists on camylofin in their clinical practice. The subsequent sections will review in detail only the clinical studies, while briefly touching upon preferences study involving gynaecologists. The first section of the review elaborates the role of camylofin and its combinations in the management of abdominal colic, while the later section elaborates on the role of camylofin in augmentation of labor.

\section{Camylofin and its combinations in abdominal colic}

Abdominal colic is a sharp, localized abdominal pain that increases, peaks, and subsides and is associated with numerous diseases of hollow viscera. Colicky pain is usually attributable to spasm of a tubular structure, often around a blockage. Colicky pain is therefore more commonly biliary, intestinal, or ureteric in origin. ${ }^{9,10}$ Camylofin is an anti-spasmodic that can relieve colicky pain due to its potent dual mode of action, i.e. musculotropic and neurotropic actions for smooth muscle relaxation. Thus, on one hand, Camylofin has a direct papaverine like spasmolytic action on the smooth muscle, where it inhibits the enzyme phosphodiesterase, which in turn causes an increase in concentration of cyclic AMP and smooth muscle relaxation. On the other hand, it has a mild atropine like anticholinergic action also, making it one of the most potent antispasmodics., ${ }^{3,411-14}$ In India, plain camylofin is available in the injectable form and oral drops formulations. It is also available as a combination with paracetamol (as tablets and syrup), with mefenamic acid (as tablets), with diclofenac (as injection and tablets) and also with nimesulide (as tablets). There is data to support the use of camylofin and its combination in different types of colic like GI colic, menstrual colic, renal colic and biliary colic. In the subsequent sections, clinical trial evidence on the above-mentioned formats and formulations of camylofin is reviewed in detail to ascertain its role in the management of abdominal colic, with reference to women patients.

\section{Camylofin Injection in abdominal colic of various origins $^{3}$}

The clinical efficacy and tolerability of camylofin injection was studied by C. Gupta, in 209 Indian patients in a multi-centric trial involving 35 investigators. The study intervention involved camylofin $25 \mathrm{mg}(1 \mathrm{~mL})$ given as a slow i.v. injection over a period of one minute. However, this is only half of the generally recommended dosage of camylofin injection which is $50 \mathrm{mg}(2 \mathrm{~mL})$. Also, in contrast to the route of administration employed in this study, camylofin is generally recommended to be given as an intramuscular injection. The study enrolled patients of both genders, with 73 patients of intestinal colic, 88 patients of renal colic, 36 patients of biliary colic and 12 patients of menstrual colic. Overall, the study reported a good response to camylofin therapy in $95 \%$ of the patients. In patients with intestinal colic, 68 of the 73 patients reported a 'moderate' to 'severe' pain at baseline. Overall, $67(91 \%)$ of these patients reported good pain relief after treatment with camylofin. In 13 patients, the dose of camylofin had to be repeated. In patients with renal colic, 84 of the 88 patients reported a 'moderate' to 'severe' pain at baseline. Overall, 83 (94\%) of these patients reported good pain relief after treatment with camylofin. In 29 patients, the dose of camylofin had to be repeated. In patients with biliary colic, all of the 36 enrolled patients reported a 'moderate' to 'severe' pain at baseline. Overall, $33(91 \%)$ of these patients reported good pain relief after treatment with camylofin. In 15 patients, the dose of camylofin had to be repeated. Lastly, in patients with menstrual pain, 10 of the 12 patients reported a 'moderate' to 'severe' pain at baseline. All 12 $(100 \%)$ of these patients reported good pain relief after treatment with camylofin, with a repeat dose given in 2 patients.

Thus, the investigators concluded that camylofin injection is a very effective treatment for symptomatic relief of abdominal colic, with relatively few and mild adverse effects.

\section{Camylofin-diclofenac injection versus in hyoscine injection in renal (ureteric) colic $^{15}$}

Rajesh Kumar et al studied the comparative efficacy and tolerability of a fixed dose combination of camylofin dihydrochloride and diclofenac injection with hyoscine butyl bromide injection. 122 adult patients, both male and female, suffering from pain due to ureteric colic, were enrolled in this open label, parallel, randomized, multi- 
centric trial. The study subjects were randomly allocated to either hyoscine $20 \mathrm{mg}$ ( $1 \mathrm{~mL}$ ) or camylofin $50 \mathrm{mg}$ plus diclofenac $50 \mathrm{mg}(2 \mathrm{~mL})$ intramuscular injections. The study results suggested that the fixed dose combination of camylofin and diclofenac had a quicker ( 30\% faster) onset of pain relief compared to hyoscine. Also, 15 minutes' post injection, the mean VAS scale scores in camylofin-diclofenac group had significantly fallen by $50 \%$, as compared to the hyoscine group which approached only $16 \%$ decline (not significant) in mean VAS scores at 15 minutes. This difference in VAS scores between the two groups was also statistically significant. $(p<0.05)$. Also, the hyoscine group approached $\sim 50 \%$ pain relief only at 90 minutes, by which time the camylofin-diclofenac group showed $90 \%$ pain relief. The duration of pain relief was not reported in the study, but at the last measured time point i.e. 180 minutes ( $3 \mathrm{hrs}$ ) almost complete $(99 \%)$ pain relief was reported in the camylofin-diclofenac group as compared to only $76 \%$ pain relief in the hyoscine group. The difference in pain relief between the two groups was significant at all time points. Thus, the investigators concluded that camylofindiclofenac injection provides a significantly faster and a greater pain relief in patients with renal (ureteric) colic. On the tolerability front, also, the camylofin-diclofenac group reported only $5 \%$ adverse events in comparison to the hyoscine group, which reported $18 \%$ adverse events. Even anti-cholinergic side effects like dryness of mouth were reported in only $1.6 \%$ patients in the camylofindiclofenac group as compared to $10 \%$ in the hyoscine group.

Camylofin-paracetamol oral combination versus dicyclomine-paracetamol combination in abdominal colic of gastrointestinal, hepatobiliary, and renal origins $^{16}$

Mohammed Ali et al studied the comparative efficacy of an oral fixed dose combination of camylofin-paracetamol $(25 \mathrm{mg}+300 \mathrm{mg})$ and oral dicyclomine-paracetamol combination $(20 \mathrm{mg}+500 \mathrm{mg})$ in the management of mild to moderate colic and spasmodic abdominal pain in Indian patients. The study was an open label, randomized, comparative study enrolling 50 patients (both male and female) suffering from abdominal spasmodic pain due to various origins like cholecystitis, cholangitis, GI infections, gastritis, appendicitis and renal colic. The study results showed that for the primary end point (reduction in mean / percentage VAS scores) there was a higher reduction of pain (VAS) scores in the camylofin-paracetamol arm compared to the dicyclomine-paracetamol arm, on both day $3(-38.4 \% \mathrm{Vs}$ $-35.2 \% ; \mathrm{p}=0.015)$ and day $5 \quad(-77.8 \%$ Vs $-50.6 \%$; $\mathrm{p}=0.0001)$. Similarly, a statistically significant higher reduction in the total scores (i.e. tenderness, abdominal rigidity and inflammation scores was seen in the camylofin- paracetamol arm compared to the dicyclomine-paracetamol arm, on day $3(-61.5 \% \mathrm{Vs}-$ $82.9 \% ; \mathrm{p}=0.01)$ and day $5(-88.5 \% \mathrm{Vs}-100 \% ; \mathrm{p}=0.0001)$. On the global efficacy scale ratings by the patients, the camylofin-paracetamol combination was rated as 'Good' to 'Very Good' by $95.2 \%$ patients as against $42.1 \%$ patients for the dicyclomine- paracetamol group $(\mathrm{p}=0.001)$. On the global scale ratings for tolerability by the patients, the camylofin-paracetamol combination was rated as 'Good' by $80.95 \%$ patients as against $78.95 \%$ patients for the dicyclomine-paracetamol group, the results not attaining statistical significance. Noteworthy in this study is the fact that the camylofin combination demonstrated superior efficacy compared to the dicyclomine combination, despite the fact that the camylofin combination contained $300 \mathrm{mg}$ of paracetamol as against the dicyclomine combination which contained $500 \mathrm{mg}$ of paracetamol.

\section{Camylofin-mefenamic acid combination versus dicyclomine-mefenamic acid combination in patients of primary dysmenorrhea (menstrual colic) ${ }^{8}$}

Dhandapani S et al, 2017 reported the results of a randomized comparative clinical study evaluating the efficacy and tolerability of an oral fixed dose combination of camylofin-mefenamic acid and oral dicyclomine-mefenamic acid. The single centre study enrolled 50 women suffering from primary dysmenorrhea, who were randomly allocated to receive either a combination of camylofin dihydrochloride $50 \mathrm{mg}$ and mefenamic acid $250 \mathrm{mg}$ or a combination of dicyclomine $10 \mathrm{mg}$ and mefenamic acid 250mg. The study medications were given T.I.D for five days and evaluation was done at base line, day three and day five. The results showed that in the camylofin-mefenamic acid group the VAS scores reduced by $86 \%$ on day 3 and almost $100 \%$ on day 5 , where as in the dicyclominemefenamic acid group, there was a marginally less decrease in VAS scores by $82 \%$ on day 3 and $95 \%$ on day 5. Patients with complete pain relief at study end were almost $96 \%$ and $88 \%$ patients in the two groups respectively. Global assessment of efficacy by the investigator showed that $73 \%$ of the patients in the camylofin-mefenamic acid group were rated as 'Very Good' to 'Excellent' as compared to $54 \%$ of the patients in the dicyclomine-mefenamic acid group. Although, the findings suggest that camylofin-mefenamic acid is a better alternative to dicyclomine- mefenamic acid in the management of menstrual colic (primary dysmenorrhea), it must be noted that these findings did not attain statistical significance $(\mathrm{p}>0.05)$.

\section{Camylofin and its role in augmentation of labor}

Camylofin is a drug that has been recommended for acceleration of labor for more than six decades. There is a growing body of evidence to support the efficacy and tolerability of Camylofin in the active management of labor. ${ }^{4}$ Camylofin primarily acts on the smooth muscles and is a preferential cervical dilator, with no interference on the uterine contractions. Camylofin does not interfere with uterine contractility due to its phosphodiesterase IV iso-enzyme selectivity. Owing to this preferential cervical 
dilating action, camylofin is used for accelerating the first stage of labor. ${ }^{4,13}$ Camylofin shortens the duration of labor in primigravidas by $40 \%$ and multigravidas by $24 \% .4,11$ In addition, camylofin has the following properties which strongly support its use in augmentation of labor. Firstly, it has a prompt action, i.e. at a dose of $50 \mathrm{mg}$ i.m, the onset of action begins in 15-20 minutes. It also has a long duration of action, i.e. at a dose of $50 \mathrm{mg}$ i.m. the action lasts for 4-5 hours. ${ }^{4,11}$ In clinical studies, camylofin gives superior results with just a single dose compared to other molecules like drotaverine, hyoscine and valethamate, where multiple (2-3) doses are required. ${ }^{4}$ Clinical studies have suggested that camylofin is a preferential cervical dilator, with no effect on uterine contractility and it has a good feto-maternal tolerability profile. Camylofin can also be used in cases of uterine inertia. $^{4,13}$ In active management of labor, when given along with drugs like tramadol, it provides enhanced analgesia to the mother. ${ }^{4,5}$ In the subsequent sections, clinical evidence on camylofin in Indian patients for augmentation of labor is reviewed. These include both placebo-controlled studies as well as studies with active comparators.

\section{Camylofin vs placebo in augmentation of labor ${ }^{4,13}$}

Warke et al, 2004 reported the results of a randomized placebo controlled-trial enrolling 100 primigravidas to evaluate the efficacy and tolerability of camylofin in active phase of labor. Camylofin (50mg i.m) and placebo were administered as a single dose. For the primary end point, which was the time from onset of active labor (3 $\mathrm{cm}$ cervical dilatation) to full cervical dilatation, the effect of camylofin was significantly superior to placebo (Average time to full cervical dilatation -3 hours 35 minutes Vs 5 hours 34 minutes; $\mathrm{p}<0.001$ ). There was a reduction of almost 2 hours in average duration of active phase of first stage of labor in patients receiving camylofin. For the secondary outcome measure, i.e. rate of cervical dilatation, camylofin was significantly better than placebo. (1.92cm/hour Vs $1.18 \mathrm{~cm} /$ hour; $\mathrm{p}<0.001)$.

\section{Camylofin vs drotaverine in augmentation of labor ${ }^{4,17}$}

Uday $\mathrm{R}$ et al investigated the comparative efficacy of camylofin and drotaverine in 126 primigravidae in augmentation of active phase of labor. The groups were randomly allocated to either camylofin injection i.m (dose)or drotaverine hydrochloride i.v. (dose). Camylofin demonstrated a significantly superior effect on the cervical dilatation rate $(1.78 \mathrm{~cm} /$ hour $\mathrm{Vs} 1.61 / \mathrm{hr}$; $\mathrm{p}=0.002)$. Noteworthy is the fact that $\sim 95 \%$ of camylofin group subjects delivered with only one injection, compared to the drotaverine group, where two injections were needed in $92 \%$ of the cases. $(p<0.001)$. The mean induction-delivery' interval was significantly shorter in the camylofin group compared to the drotaverine group (207.96 minutes Vs 228.38 minutes; $\mathrm{p}<0.05$ ). The mean duration of active phase of first stage of labor was also shorter in camylofin group (332.54 minutes Vs 356.78 minutes), but this difference was not statistically significant. The study results concluded that camylofin has a superior efficacy compared to drotaverine in cervical dilatation and shortening of labor.

\section{Camylofin vs hyoscine in augmentation of labor ${ }^{4,18}$}

Dayama et al, 2016 reported the superior efficacy of camylofin compared to hyoscine in a randomized controlled trial enrolling 150 primigravida women. The subjects were randomized into three groups of 50 each, the control group or camylofin group (i.m, dose) or hyoscine group (i.v, dose). The study results showed that camylofin has a superior effect on the cervical dilatation compared to both hyoscine $(3.14 \mathrm{~cm} / \mathrm{hr}$ vs $2.78 \mathrm{~cm} / \mathrm{hr}$; $\mathrm{p}<0.001)$ and control group $(3.14 \mathrm{~cm} / \mathrm{hr}$ vs $1.97 \mathrm{~cm} / \mathrm{hr}$; $\mathrm{p}<0.001)$. Camylofin also demonstrated a statistically significant shortening of both 1st and 3rd stages of labor compared to the hyoscine group $(\mathrm{p}<0.05)$ and the control group $(\mathrm{p}<0.001)$.

\section{Camylofin vs valethamate in augmentation of labor ${ }^{4,19}$}

Kaur D et al conducted a study comparing the efficacy and tolerability of camylofin and valethamate. The study enrolled 200 women who were allocated to receive either one injection of camylofin or three injections (hourly) of valethamate. The investigators reported that the injection delivery interval was significantly shortened in the camylofin group, however, the quantitative findings are not available. The investigators also reported that all neonates in both groups had an APGAR score of 9 at five minutes. On the tolerability front, also the investigators suggested the camylofin had fewer side effects compared to valethamate. Overall, the study concluded that camylofin is significantly superior to valethamate in shortening the first stage of labor.

\section{Camylofin vs hyoscine and valethamate combination in augmentation of labor ${ }^{4,20}$}

Sarbhjit Kaur et al studied the comparative efficacy of camylofin (intramuscular/25mg single dose) compared to a combination of valethamate bromide and hyoscine butyl bromide (intra-muscular injection of Valethemate bromide (Epidosin) (1 amp) + injection Hyoscine $\mathrm{N}$ Butyl bromide (Buscopan) (1 amp) were given at half hourly interval of 3 doses). This study marks special attention as it is the only study that compares the efficacy of a single dose of camylofin with a combination of two anti-spasmodics given in multiple doses. The study enrolled 200 women, (primi and multigravidae) randomized to receive either camylofin or a combination of valethamate + hyoscine. Results showed that the mean rate of cervical dilatation was significantly higher in camylofin group compared to the valethamate + hyoscine group, (3.33 cm/hr Vs $2.69 \mathrm{~cm} /$ hour; p<0.01). The duration of active phase of 1 st stage of labor was also significantly shorter in the camylofin group compared to valethamate + hyoscine group (141.40 \pm 55.41 minutes Vs 
$181.46 \pm 75.58$ minutes; $\mathrm{p}<0.01)$. The mean duration of 'injection-delivery' interval was also significantly shorter in camylofin group as against in valethamate + hyoscine group (172.05 \pm 60.82 minutes Vs $211.89 \pm 75.86$ minutes; $\mathrm{p}<0.01)$. These results show that camylofin is a potent and effective drug for augmentation of labor, despite being given in a single dose and being compared with a combination of antispasmodics in augmentation of labor. 15All the above clinical study results resonate in the findings of a recent survey with gynaecologists across the country, which showed that camylofin is considered as the anti-spasmodic most suitable for female patients compared to drotaverine, dicyclomine and hyoscine. ${ }^{21}$

\section{CONCLUSION}

Anti-spasmodics have a key role to play to ensure better outcomes in both the above-mentioned conditions, i.e. spasmodic abdominal pain (abdominal colic) and augmentation of labor. While there are several antispasmodic options available like drotaverine, camylofin, hyoscine, dicyclomine, valethamate etc. for the above said purpose, it is essential to know which amongst these will help the clinician deliver better health outcomes.

As elaborated in the review sections above, camylofin seems to score over the rest of the anti-spasmodics in key efficacy and tolerability parameters, both in the management of abdominal spasmodic pain as well as for augmentation of labor. Camylofin is-an antispasmodic that has been in use in India for almost six decades. There is good clinical evidence with Indian patients for the use of both camylofin and its combinations in these indications, in the injectable as well as oral forms. In all the clinical studies comparing the efficacy of camylofin with other anti-spasmodics in augmentation of labor, camylofin demonstrated a statistically significant superiority, suggesting that camylofin has a higher spasmolytic potency compared to other anti-spasmodics like drotaverine, hyoscine and valethamate. This is further reinforced by the fact that in some studies, camylofin maintained the superior efficacy, despite being given as a single dose compared to repeat doses of comparator drugs. Further reassuring are the study results in augmentation of labor, where camylofin single dose demonstrated superior efficacy in augmentation of labor, even when the comparator arm was given a combination of two anti-spasmodic drugs i.e. hyoscine and valethamate, in three doses at hourly intervals. The higher potency of camylofin as a spasmolytic is also reflected in the results from clinical studies in abdominal colic pain. Noteworthy is the clinical study in abdominal colic patients, comparing a camylofin-paracetamol combination with a dicyclomine-paracetamol combination, which revealed statistically significant superiority of the camylofin combination, this despite the camylofin combination containing 300mg paracetamol as compared to the dicyclomine combination containing $500 \mathrm{mg}$ paracetamol. Similar results, highlighting better outcomes in abdominal colic of different types, was shown in studies comparing camylofin-diclofenac combination compared with hyoscine (in renal colic) and also camylofin-mefenamic acid combination compared with dicyclomine-mefenamic acid combination (in menstrual colic). Given the availability of strong clinical trial data in Indian women patients, superior efficacy as monotherapy as well as in combinations with NSAIDs, superior outcomes across different clinical conditions like gastrointestinal colic, renal colic, biliary colic, menstrual colic and augmentation of labor, and the preference of gynaecologists as an option suitable for women patients, camylofin along with its combinations holds a strong place in the armamentarium of practicing obstetricians and gynaecologists and can be a preferred choice of therapy in treatment protocols of abdominal spasmodic pain and augmentation of labor.

\section{Funding: No funding sources Conflict of interest: None declared \\ Ethical approval: Not required}

\section{REFERENCES}

1. Brock N. Pharmacology of Avacan. Dtsch Med Wochenschr. 1951;76(14):474-7.

2. Tadashi M, Koichi Y. A study of metabolism of Isoamyl-alpa-N-(betadiethylaminoethyl)-

Aminophenylacetate-(Avacan). Jap J Pharmacol. 1956;5 (2):122-31.

3. C Gupta. Use of Anafortan Intravenous Injection for Treatment of Colicky Pain. J Indian Med Assoc.2000;98(8):479-80

4. Mayadeo N, Gangadhar A, Das S. Camylofin in the management of prolonged labor: A review of evidence. Int J Reprod Contracept Obstet Gynecol. 2017;6(3):776-80.

5. Daftary SN, Desai SV, Thanawala U, Bhide A, Levi J, Patki A et al. Programmed Labor: Indegenous Protocol to Optimize Labor Outcome. South Asian Fed Obstet Gynecol. 2009;1(1):61-4

6. S. Bachani, S. Topden, Active management of labor in a low-resource setting and its impact on cesarean section rates. Int J Gynecol Obstet. 2006;94(1):54-5

7. Unpublished Data: The Drugs Controller, India Letter of permission to import 'Avacan' dated 23rd October 1958. Courtesy-Abbott Healthcare Private Limited.

8. Dhandapani S, Gangadhar A, Das S. A Randomised, comparative study to evaluate the efficacy and tolerability of two fixed dose combinations of Camylofin \& Mefenamic acid and Dicyclomine \& Mefenamic acid in the management of Primary Dysmenorrhea. The Indian Practitioner. 2017;70(2) :16-20.

9. Gray J, Wardrope J, Fothergill DJ. 7 abdominal pain, abdominal pain in women, complications of pregnancy and labour. Emer Med J. 2004;21(5):60613. 
10. Cartwright SL, Knudson MP. Evaluation of Acute Abdominal Pain in Adults. Am Fam Physician. 2008;77(7):971-8.

11. Selected Topics in Obstetrics and Gynaecology for Postgraduates and Practitioners. Available at https://senscot.net/selected-topics-in-obstetrics-andgynaecology-2-for-postgraduates-andpractitioners.pdf

12. Talapatra SK, Talapatra B. Atropine $[( \pm)$ Hyoscyamine] and Cocaine (Ornithine-Derived Alkaloids). InChemistry of Plant Natural Products 2015 (pp. 767-780). Springer, Berlin, Heidelberg.

13. Warke HS, Chauhan AR, Raut VS, Ingle KM, Efficacy of camylofin dihydrochloride in acceleration of labour. A randomised double blind trial. Bombay Hospital J. 2003;45(3)420-3

14. Kamel AH, Mahmoud WH, Mostafa MS. Selective recognition in potentiometric sensing based on two competitive recognition sites for static and hydrodynamic determination of camylofin as a smooth muscle relaxant. Eur Chem Bull. 2013;2(2):88-93.

15. Rajesh K, Sameer R. A Comparative Efficacy and Safety Study of Injection Anaspas and Injection Hyoscine in the Management of Ureteric Colic - A Parallel Study in 122 Patients. AMA-India. 2004;3 (7):67-9.

16. Ali M, Naik M. Open, randomized comparative study to evaluate efficacy, safety and tolerability of Anafortan Vs. dicyclomine+paracetamol in treatment of mild to moderate abdominal colic and spasmodic abdominal pain. Indian Med Gazette.2010:314-21.
17. Rajani U, Binu P. A Randomized Comparative Study of Intramuscular Camylofin.

18. Dihydrochloride and Intravenous Drotaverine Hydrochloride on Cervical Dilatation in Labor. Indian Clinic Prac. 2015;26(6):558-63

19. Dayama SS, Patil SS, Sambarey PW. A randomised controlled study of intramuscular camylofin dihydrochloride vs intravenous hyoscine butylbromide in augmentation of labour. Global Med Res: Gynecol Obstet. 2016;16(1):1-6

20. Kaur D, Kaur A. "Anafortan" an old drug with its newer use in acceleration of labour [abstract]. 49th All India Congress of Obstetrics and Gynaecology; 2006 January 6-9; Cochin, Kerala State, India. 2006:59.

21. Kaur S, Bajwa SK, Kaur P, Bhupal S. To compare the effect of camylofin dihydrochloride (anafortin) with combination of valethamate bromide (epidosin) and hyoscine butyl-n-bromide (buscopan) on cervical dilation. Clin Diag n Res. 2013;7(9):1897-9.

22. Gangadhar A, Das S. Abdominal Colic in Gynaecological Practice: A cross sectional survey of practices and preferences in the diagnosis and management of abdominal colic in Indian women and usage of Anafortan Tablets in gynaecological practice. Indian Practitioner. 2018;71(1):17- 22.

Cite this article as: Mayadeo N. Role of camylofin and its combinations in obstetrics and gynaecological practice: a review of Indian evidence. Int J Reprod Contracept Obstet Gynecol 2019;8:343-8. 